\title{
Gender characteristics of psychological well-being and personality values in modern high school students
}

Z. Shaekhov, O. Tikhomandritskaya, N. Malysheva, N. Kabalnov

Department of Social Psychology, Faculty of Psychology, Lomonosov Moscow State University, Moscow, Russia

The aim of the study is to establish gender differences in the system of personality values and in the indicators of PWB in role of value orientations in PWB for high school students.

Participants. 69 high school students (32 boys and 37 girls) 16-17 years old from schools of Kazan and Ufa took part in this study.

\section{Theoretical and methodological aspect}
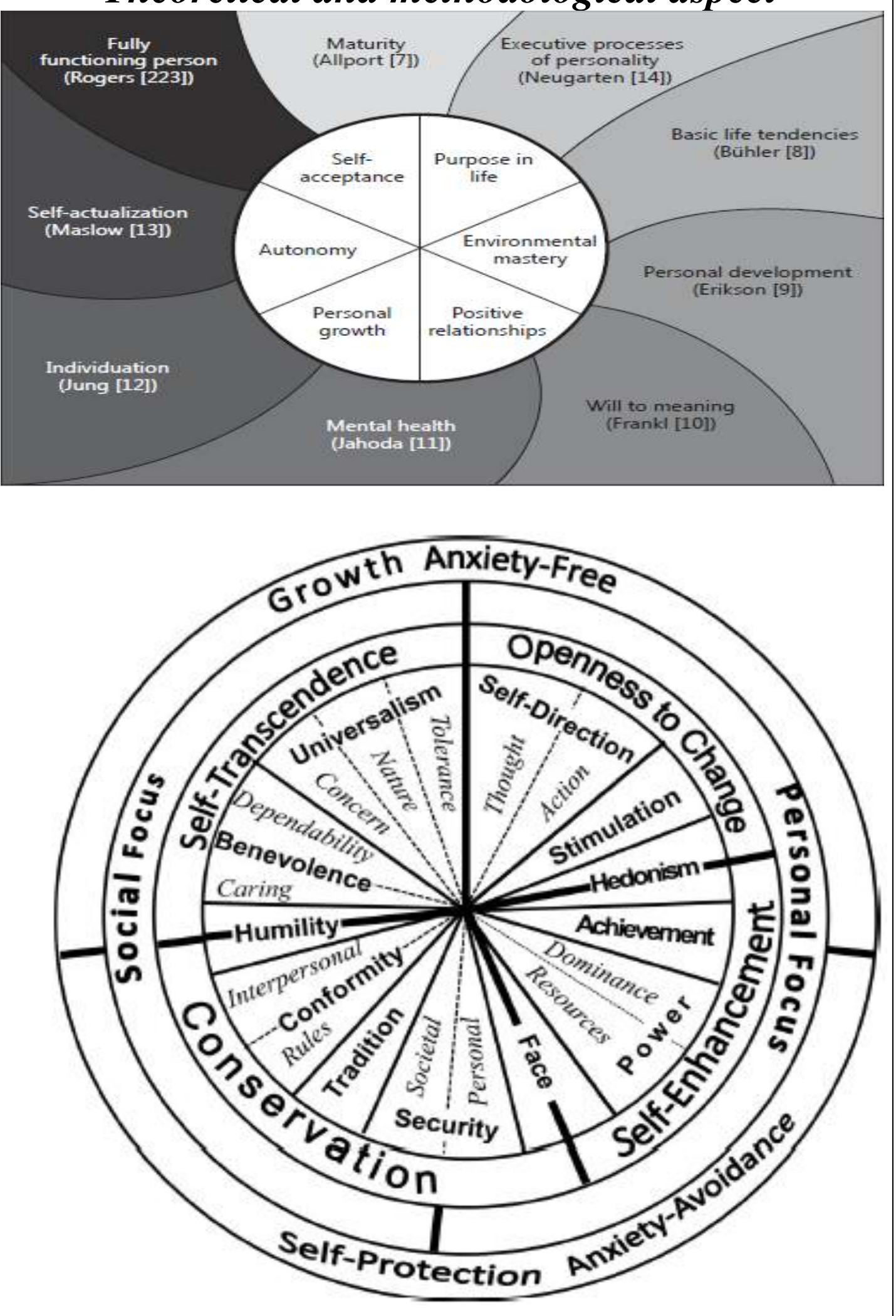

Results of research values. The most important values 1 level for male is «Universalism-Nature» $(\mathrm{M}=, 395, \mathrm{SD}=, 764)$, for female «Benevolence-Care» $(\mathrm{M}=, 732, \mathrm{SD}=, 594)$

There are several values like Self-direction Action, Hedonism, Universalism - Concern, Universalism - Tolerance, Benevolence - Care, Benevolence - Dependability in the gender differences in the 1 st level values. Females have more these values than males. However, males have higher values than females like Power - Dominance, Power - Resources, Conformity - Rules contrary.

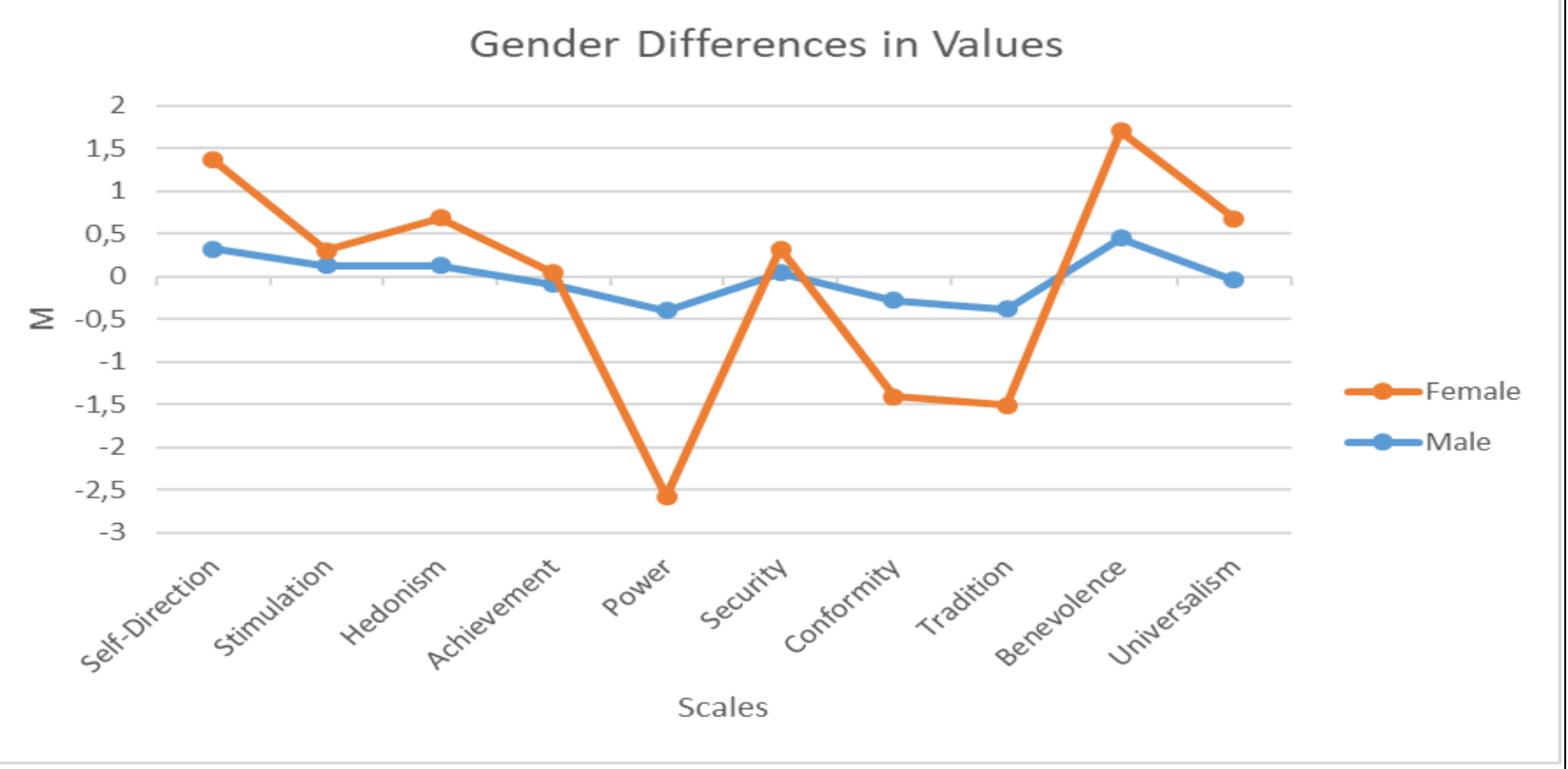

Results of research PWB. The next step was a comparative analysis of different gender groups using the PWB scales. It was shown that on all scales PWB indicators are higher for girls than for boys, which is reflected in the value for the integral scale of well-being. It is possible to conclude that girls feel more psychologically prosperous than boys.

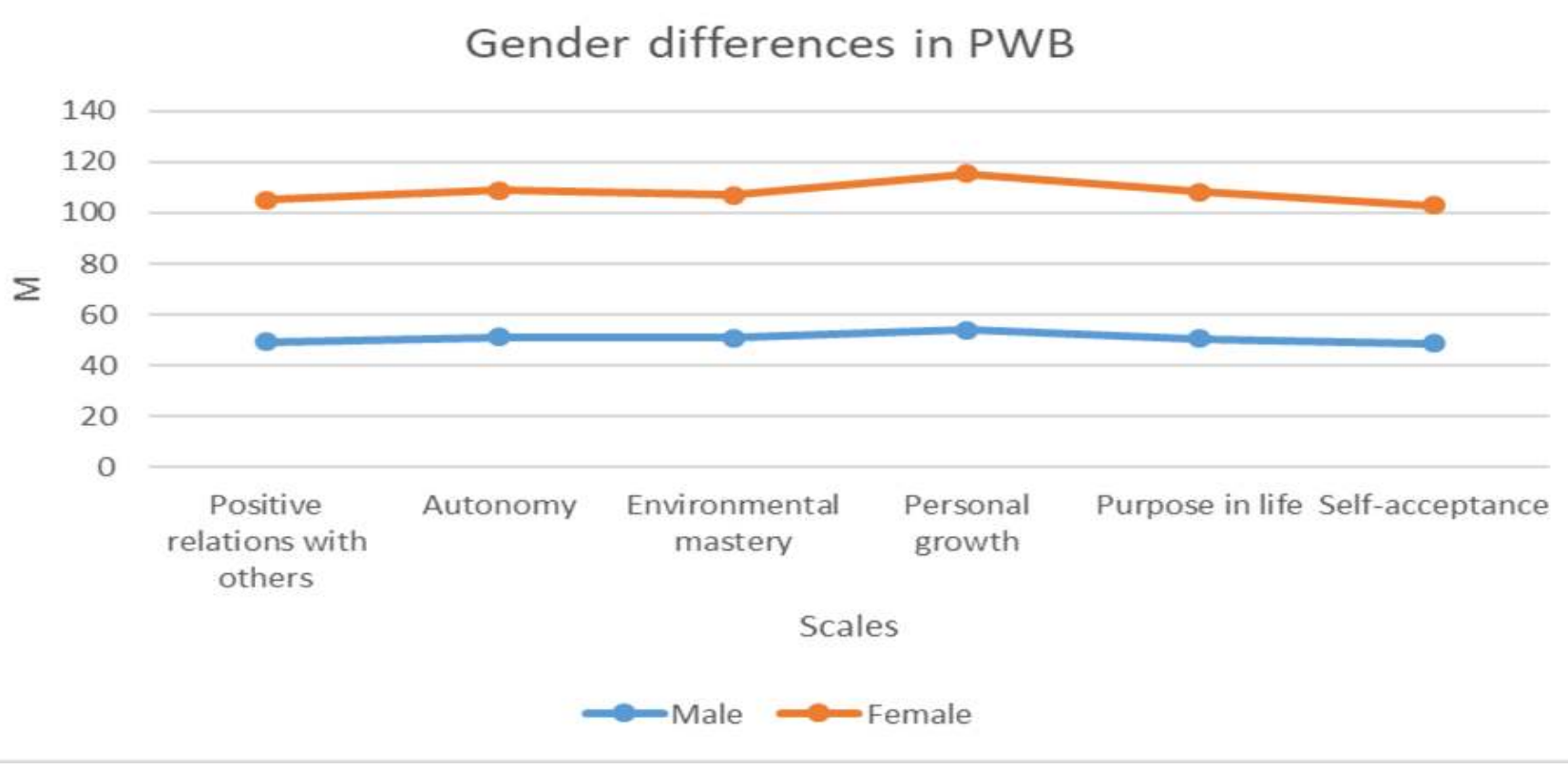

Correlation of PWB and personality values in boys

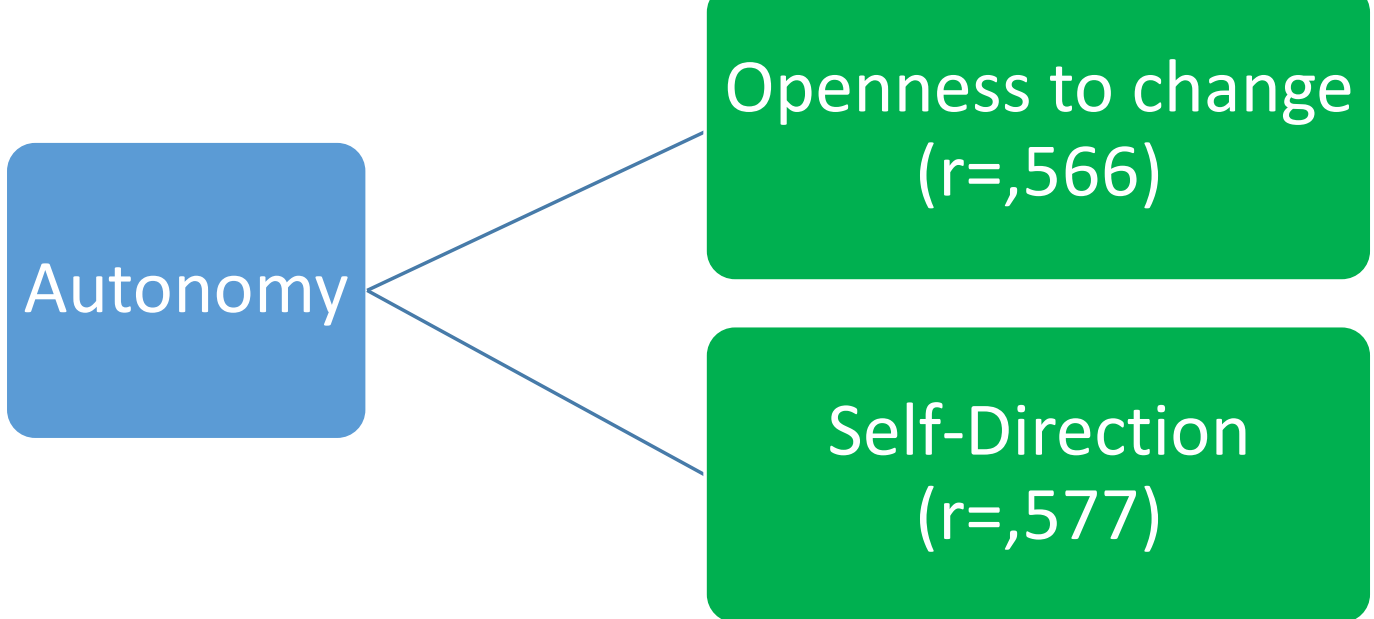

$\mathrm{p}=, 001$; blue $-\mathrm{PWB}$, green - values

Correlation of PWB and personality values in girls

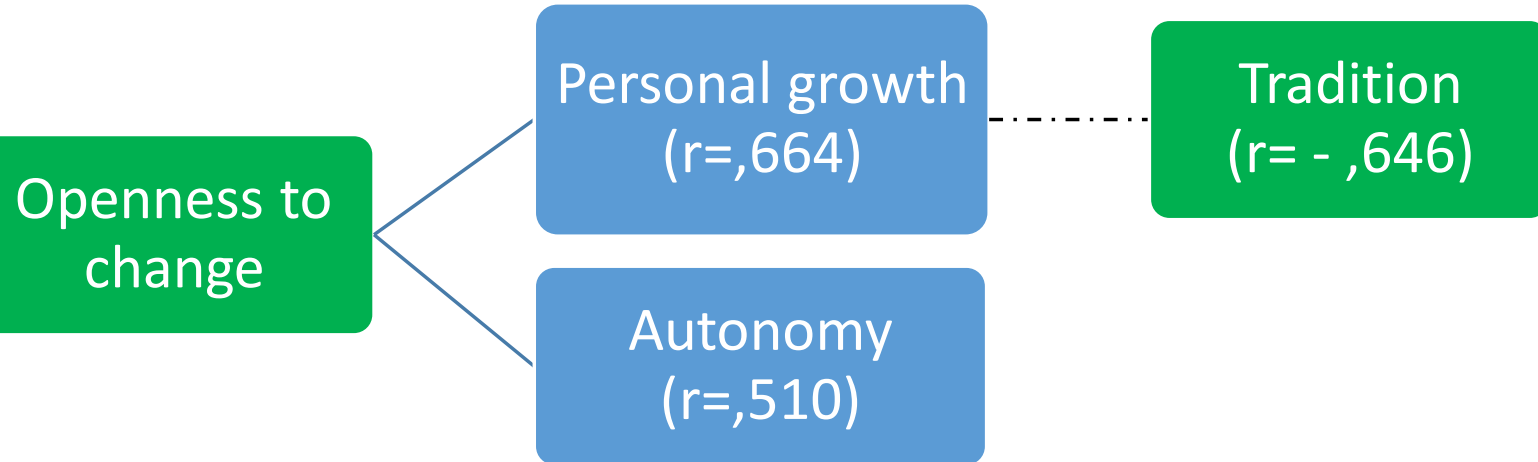

$\mathrm{p}=, 001$; blue $-\mathrm{PWB}$, green - values.

Discussion. Gender differences in the value orientations of boys and girls are determined by the fact that boys are ready to achieve the goal of ensuring the prosperous existence of all people and the whole world around them, while girls are aimed at ensuring the well-being of, above all, people close to them who belong to the same group. In general, PWB is higher in girls than in boys. The main differences in the PWB indicators between boys and girls were set according to the scales "Personal growth" and "Purpose in life".

To achieve their well-being, boys and girls see the need to focus on themselves, to be open to change, to accept everything new, to show independence.

The study was supported by Russian Foundation for Basic Research, project 18-013-01206 "Sociocultural and gender factors of psychological well-being of the 21 st century generation" 